\title{
Merging cranial histology and 3D-computational biomechanics: a review of the feeding ecology of a Late Triassic temnospondyl amphibian
}

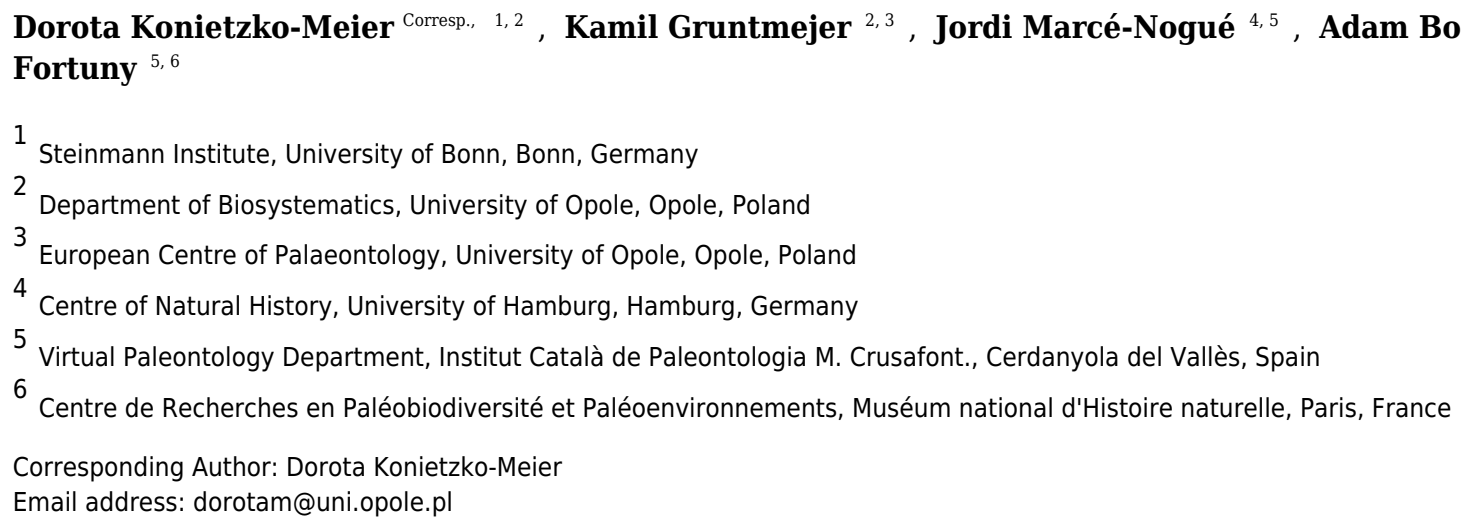

Finite Element Analysis (FEA) is a useful method for understanding form and function. However, modelling of fossil taxa invariably involves assumptions as a result of preservation-induced loss of information in the fossil record. To test the validity of predictions from FEA, given such assumptions, these results could be compared to independent lines of evidence for cranial mechanics. In the present study a new concept of using bone microstructure to predict stress distribution in the skull during feeding is put forward and a correlation between bone microstructure and results of computational biomechanics (FEA) is carried out. The bony framework is a product of biological optimisation; bone structure is created to meet local mechanical conditions. To test how well results from FEA correlate to cranial mechanics predicted from bone structure, the well-known temnospondyl Metoposaurus krasiejowensis was used as a model. A crucial issue to Temnospondyli is their feeding mode; did they suction feed or employ direct biting, or both? Metoposaurids have previously been characterised either as active hunters or passive bottom dwellers. In order to test the correlation between results from FEA and bone microstructure, two skulls of Metoposaurus were used, one modelled under FE analyses, while for the second one 17 dermal bone microstructure were analysed. Thus, for the first time, results predicting cranial mechanical behaviour using both methods are merged to understand the feeding strategy of Metoposaurus. Metoposaurus appears to have been an aquatic animal that exhibited a generalist feeding behaviour. This taxon may have used two foraging techniques in hunting; mainly bilateral biting and, to a lesser extent, lateral strikes. However, bone microstructure suggests that lateral biting was more 
frequent than suggested by Finite Element Analysis (FEA). One of the potential factors that determined its mode of life may have been water levels. During optimum water conditions, metoposaurids may have been more active ambush predators that were capable of lateral strikes of the head. The dry season required a less active mode of life when bilateral biting is particularly efficient. This, combined with their characteristically anteriorly positioned orbits, was optimal for ambush strategy. This ability to use alternative modes of food acquisition, independent of environmental conditions, might hold the key in explaining the very common occurrence of metoposaurids during the Late Triassic. 
1 Merging cranial histology and 3D-computational biomechanics: a review of the feeding ecology of a Late Triassic temnospondyl amphibian

3

4 Dorota Konietzko-Meier ${ }^{1,2, *}$, Kamil Gruntmejer, ${ }^{2,3}$, Jordi Marcé-Nogué ${ }^{4,5}$, Adam Bodzioch ${ }^{2}$, Josep Fortuny ${ }^{5,6}$

6

$7 \quad{ }^{1}$ Steinmann Institute, University of Bonn, Nussallee 8, 53115 Bonn, Germany

$8 \quad{ }^{2}$ Department of Biosystematics, Opole University, Oleska 22, 45-052 Opole, Poland

$9 \quad{ }^{3}$ European Centre of Palaeontology, Oleska 48, 45-052 Opole, Poland

$10{ }^{4}$ Centre of Natural History (CeNak), University of Hamburg, Martin-Luther-King-Platz 3,

1120146 Hamburg, Germany

12 Institut Català de Paleontologia Miquel Crusafont, ICTA-ICP Building, c/ de les Columnes, s/n, 1308193 Cerdanyola del Vallès, Spain

$14{ }^{6}$ Centre de Recherches en Paléobiodiversité et Paléoenvironnements, Muséum national d'Histoire 15 naturelle, Bâtiment de Paléontologie, CP38, 8 rue Buffon, 75005 Paris, France

$16 *$ Address for correspondence (E-mail: dorotam@uni.opole.pl) 
27 Finite Element Analysis (FEA) is a useful method for understanding form and function.

28 However, modelling of fossil taxa invariably involves assumptions as a result of preservation-

29 induced loss of information in the fossil record. To test the validity of predictions from FEA,

30 given such assumptions, these results could be compared to independent lines of evidence for

31 cranial mechanics. In the present study a new concept of using bone microstructure to predict

32 stress distribution in the skull during feeding is put forward and a correlation between bone

33 microstructure and results of computational biomechanics (FEA) is carried out. The bony

34 framework is a product of biological optimisation; bone structure is created to meet local

35 mechanical conditions. To test how well results from FEA correlate to cranial mechanics

36 predicted from bone structure, the well-known temnospondyl Metoposaurus krasiejowensis was

37 used as a model. A crucial issue to Temnospondyli is their feeding mode; did they suction feed or

38 employ direct biting, or both? Metoposaurids have previously been characterised either as active

39 hunters or passive bottom dwellers. In order to test the correlation between results from FEA and

40 bone microstructure, two skulls of Metoposaurus were used, one modelled under FE analyses,

41 while for the second one 17 dermal bone microstructure were analysed. Thus, for the first time,

42 results predicting cranial mechanical behaviour using both methods are merged to understand the

43 feeding strategy of Metoposaurus. Metoposaurus appears to have been an aquatic animal that

44 exhibited a generalist feeding behaviour. This taxon may have used two foraging techniques in

45 hunting; mainly bilateral biting and, to a lesser extent, lateral strikes. However, bone

46 microstructure suggests that lateral biting was more frequent than suggested by Finite Element

47 Analysis (FEA). One of the potential factors that determined its mode of life may have been

48 water levels. During optimum water conditions, metoposaurids may have been more active 
49 ambush predators that were capable of lateral strikes of the head. The dry season required a less

50 active mode of life when bilateral biting is particularly efficient. This, combined with their

51 characteristically anteriorly positioned orbits, was optimal for ambush strategy. This ability to use

52 alternative modes of food acquisition, independent of environmental conditions, might hold the

53 key in explaining the very common occurrence of metoposaurids during the Late Triassic. 


\section{INTRODUCTION}

Temnospondyli is one of the most diverse groups of early tetrapods, which flourished

76 worldwide during the Carboniferous, Permian and Triassic periods and survived the Triassic-

77 Jurassic extinction as relics in eastern Asia and Australia until the Early Cretaceous (Holmes \&

78 Carroll, 1977; Milner, 1990; Warren, Rich \& Vickers-Rich, 1997; Schoch, 2013). The most

79 characteristic and best-known part of the temnospondyl skeleton is the skull. This is a flat

80 structure with few fenestrae on the skull roof (nares, orbits and, in some capitosaurs, the closed

81 otic notch); the palatal side has more extensive openings: large subtemporal windows,

82 interpterygoid vacuities and choanae. Despite extensive studies and numerous fossil records, lots

83 of issues of temnospondyl biology and mode of life still remain unclear. One crucial issue

84 concerns their mode of feeding. Temnospondyls were carnivorous, but whether they mainly used

85 suction feeding and/or direct biting is still unclear (Milner \& Sequeira, 1998; Warren, 2000;

86 Steyer et al., 2006; Witzmann, 2006; Damiani et al., 2009; Maganuco et al., 2009; Fortuny et al.,

87 2011).

A useful method for understanding form-function relationships is FEA. Over recent years, FEA has been intensively used to study the biomechanical behaviour of a wide array of vertebrates, providing new insights into the exploration of function and morphological evolution,

91 particularly adaptation and biological structural constraints (Rayfield, 2007). FEA is used to

92 obtain stress distribution patterns that can be interpreted in order to understand either mechanical

93 behaviour or evolutionary adaptation (Witzel et al., 2011). A number of studies have used

94 computational biomechanical analyses to address the question of feeding strategies among

95 Temnospondyli (Stayton \& Ruta, 2006; Fortuny et al., 2011, 2012, 2016; Marcé-Nogué et al., 96 2015; Lautenschlager, Witzmann \& Werneburg, 2016; Fortuny, Marcé-Nogué \& Konietzko- 
97 Meier, 2017). One such method, finite element analysis (FEA), documents deformation and

98 distribution of strains and stresses in the skulls that are related to different ecomorphologies

99 (Fortuny et al., 2011, 2012, 2016; Marcé-Nogué et al., 2015; Lautenschlager, Witzmann \&

100 Werneburg, 2016; Fortuny, Marcé-Nogué \& Konietzko-Meier, 2017).

101

However, computational modelling requires numerous methodological assumptions and

102 simplifications which can lead to inaccuracies or misinterpretations. This is especially true for

103 fossil taxa because of the general inability to compare the predicted scenario with results obtained

104 from living animals. A common oversimplification is to limit the number of biomechanical

105 scenarios tested (for a discussion, see Fortuny et al., 2015). For complex functions,such as

106 feeding, it is important to have scenarios additional to those performed in FEA analyses. Another

107 problem involves oversimplifications of boundary conditions and mechanical bone properties,

whether or not bones are modelled with elastic linear, homogeneous material properties, which

are calculated by using known values for the entire structure (Anderson et al., 2012; Bright,

2014). For fossil taxa without modern analogues these variables have to be assumed on the basis

111 of taxa with a similar Bauplan, even if these are only distantly related (Anderson et al., 2012) as

112 for Temnospondyli (Sanchez et al., 2010; Fortuny et al., 2016) which belong to amphibians and

113 for which commonly the genus Crocodylus is used as a proxy (see a discussion, see Fortuny et

114 al., 2016). Moreover, histological studies of metoposaurid skulls have shown that the histological

115 framework of skull bones is very variable (Gruntmejer, Konietzko-Meier \& Bodzioch, 2016),

116 which has never been taken into account during FEA analysis of fossil taxa.

This implies making assumptions regarding bone properties and input conditions (see

Bright, 2014; Fortuny et al., 2015 and references therein). The influence of these

119 oversimplifications of model construction has not yet been fully examined and is therefore poorly

120 understood. Thus, validation and testing the reliability of results using sensitivity analyses is 
121 necessary (i.e., Ross et al., 2005; Kupczik et al., 2007; Wang et al., 2010, 2012; Bright \&

122 Rayfield, 2011; Cox et al., 2011; Wood et al., 2011; Bright, 2012; Fitton et al., 2012; Walmsley et

123 al., 2013; McCurry, Evans \& McHenry, 2015). However, sensitivity analyses of a model can only

124 be carried out for extant taxa by comparing the model against data collected in vivo/in vitro. This

125 is impossible for fossil taxa, especially for those without any homologous taxa among closely

126 related extant relatives, such as Temnospondyli.

For such cases one approach to ensure reliable results may be bone histology. The bony

128 framework is a product of biological optimisation and bone structure is created to meet local

129 mechanical conditions. Bone microstructure can be used to estimate local stress. Biomechanical

130 properties of bone histology have been extensively analysed for a considerable time (i.e., Martin,

131 1991; Currey, 2003, 2006, 2012; Currey, Pitchford \& Baxter, 2007; Zioupos, Hansen \& Currey,

132 2008; Mishra, 2009; and references therein). Bone microstructure is related directly to loads and

133 can be modified during the animal's life time (short-term adaptation) and/or on the long term, as

134 an evolutionary adaptation. The mechanical properties of bone are the result of a compromise

135 between the need for a certain stiffness (i.e., to reduce deformation in the bone and achieve more

136 efficient kinematics) and the need for enough ductility to absorb impacts (i.e., to reduce the risk

137 of fracture and minimise skeletal weight), while maintaining adequate biological safety factors

138 (Biewener, 1993). The strength of a structure is the product of organisational and compositional

139 features (Currey, 2012). With regard to bone microstructure, the most important organisational

140 feature is porosity, because bone loses strength and stiffness with increased porosity. This is

141 explained by the fact that soft tissues have essentially no strength or stiffness with respect to non-

142 hydrostatic stresses (Martin, 1991). However, high cortical thickness can compensate for low

143 resistance of bone tissue (Carrier \& Leon, 1990; Margerie et al., 2004). Compact bone is

144 associated with high strength in tension, but accompanied by a lack of strength in compression, 
145 which is higher for trabecular bone (Martin, 1991; Currey, 2003; Rhee et al., 2009; Achrai \& 146 Wagner, 2013; and references therein).

A significant portion of the skeleton of early amphibians consisted of dermal bone (skull,

148 mandible, clavicle and interclavicle), either intramembranous or metaplastic in origin. Dermal

149 bone, as a specific combination of trabecular and cortical bone, forms a "sandwich-type" or

150 plywood structure which is well known in engineering for its optimum structural properties

151 (Currey, 2006). In large flat bones which are bent along their shortest dimension, the cancellous

152 bone forms the middle of a sandwich, with the compact shell bearing the major loads and the

153 cancellous bone keeping the walls of the shell apart and dealing with any shearing loads that may

154 arise. Moreover, dermal bone texture provides substantial increase in strength and stiffness that is

155 accompanied by a relatively small increase in mass (Witzmann, 2009; Rinehart \& Lucas, 2013).

156 Calculations have demonstrated that there is a property/mass advantage, albeit a modest one, in

157 having cancellous bone in the middle, rather than having a solid, but overall thinner bone

158 (Currey, 2006, 2012). A mechanical advantage of metaplastic bone is the firm connection

159 between bone and overlying soft tissue, since the collagen fibres of the attached soft tissue are

160 confluent with the collagen fibres within the metaplastic bone (Haines \& Mohuiddin, 1968).

To test whether or not FEA models and histological results provided similar predictions of

162 cranial mechanical behaviour under feeding loads, the present paper compares results from both

163 methods for a well-known taxon. The early tetrapod Metoposaurus krasiejowensis (Sulej, 2002)

164 (Metoposauridae, Temnospondyli) from the Upper Triassic of southwest Poland provides an

165 interesting case study in view of the great number of excellently preserved specimens recovered

166 as well as the extensive data set for this taxon (Sulej, 2002, 2007; Barycka, 2007; Konietzko-

167 Meier \& Klein, 2013; Konietzko-Meier \& Sander, 2013; Gruntmejer, Konietzko-Meier \& 
168 Bodzioch, 2016; Fortuny, Marcé-Nogué \& Konietzko-Meier, 2017; Teschner, Sander \& 169 Konietzko-Meier, 2017).

170 In the present study a new concept of using bone microstructure to predict stress

171 distribution in the skull during feeding is outlined and a correlation between predictions from

172 bone microstructure and computational biomechanics (FEA) results is carried out as well.

173 Merging results from these two methods will first test predictions generated by FEA and help to 174 evaluate the influence of methodological assumptions and simplifications on the final results and, 175 secondly, yield new insights into the feeding ecology of Temnospondyli.

176

177

178

179

180

181

182

183

184

185

186

187 188

189

190

191

\section{MATERIAL AND METHODS}

\section{Material}

Two skulls of Metoposaurus krasiejowensis, housed in the collections of Opole University (UOPB), were analysed. One of these (UOPB 00124; $290 \mathrm{~mm}$ in length) was CT scanned for 3D-Finite Element Analysis, while the second (UOPB 01029; $400 \mathrm{~mm}$ in length) was studied histologically (Fig. 1). Both specimens were collected at Krasiejów, the Upper Triassic locality in southern Poland (of Norian age, according to recent stratigraphical studies: Racki \& Szulc, 2015; Szulc, Racki \& Jewuła, 2015; Szulc et al., 2015).

\section{Methods}

Finite Elements Analysis- Skull UOPB 124 of Metoposaurus krasiejowensis was CT scanned at the Hospital Mutua de Terrassa (Catalonia, Spain), using a medical CT scanner Siemens Sensation 16. The specimen was scanned at $140 \mathrm{kV}$ and $150 \mathrm{~mA}$, obtaining a $0.576 \mathrm{~mm}$ pixel size and an output of 512 X512 pixels per slice with an interslice space of $0.3 \mathrm{~mm}$. The 
192 specimen corresponds to an entire skull, completely matrix filled. After segmentation, a 3D

193 model only of the skull was generated. During this last step, the surface irregularities were

194 repaired using refinement and smoothing tools from Rhinoceros 5.0 software and imported into

195 ANSYS 16.2 software to perform FEA (see Fortuny, Marcé-Nogué \& Konietzko-Meier, 2017 for

196 further details).

197 A Structural Static Analysis to evaluate the biomechanical behaviour during biting was

198 performed using the Finite Element Package ANSYS 16.2 in a Dell Precision ${ }^{\mathrm{TM}}$ Workstation

199 T7600 with $32 \mathrm{~GB}(4 \mathrm{X} 8 \mathrm{~GB})$ and $1600 \mathrm{MHz}$. Elastic, linear and homogeneous material properties

200 were assumed for the bone using the following values: E (Young's modulus): $6.65 \mathrm{GPa}$ and $\mathrm{m}$

201 (Poisson's ratio) 0.35 (Currey, 1987), from frontal bone of Crocodylus. The skull of

202 Metoposaurus krasiejowensis was meshed with an adaptive mesh of hexahedral elements

203 (Marcé-Nogué et al., 2015). The mesh of the model was around 2.2 million elements and 3.1

204 million nodes. A gape angle of $10^{\circ}$ was used, although the model was tested also under $20^{\circ}$ gape

205 angle, obtaining a very similar distribution pattern (see Fortuny, Marcé-Nogué \& Konietzko-

206 Meier, 2017 for a comparison).

207 Four loading cases were analysed considering bilateral, unilateral, lateral prehension/bite and

208 skull-raising system (Fig. 2). The bilateral case simulates a bilateral bite on both left and right

209 sides of the skull, whereas the unilateral case simulates the same bite only on the right side. The

210 lateral case simulates a lateral loading direction to generate a within-plane lateral bend to the

211 snout and simulate movement of the head through the water, assuming that Metoposaurus could

212 have hunted prey by using a rapid lateral sweep of the head during active swimming. The skull-

213 raising case considered the motion of the skull (relative to the lower jaw) when the mouth opens.

214 All cases are illustrated in Figure 2 and explained in more detail by Fortuny, Marcé-Nogué \&

$215 \quad$ Konietzko-Meier, 2017. 
216 Displacements at the jaw joint were restricted in the y-direction, simulating the contact with the

217 jaw and near the double-headed occipital condyle in the x-direction, simulating the presence of

218 the vertebral column.

219 For the bilateral and the unilateral cases, forces exerted by the Adductor Mandibulae Internus

220 (AMI), the Adductor Mandibulae Externus (AME) and the Adductor Mandibulae Posterior

221 (AMP) were considered in the model according to soft-tissue reconstruction based on several

222 authors (e.g., Carroll \& Holmes, 1980; Sulej, 2007; Steyer et al., 2010; Witzmann \& Schoch,

223 2013; Marcé-Nogué et al., 2015; Fortuny et al., 2016, Fortuny, Marcé-Nogué \& Konietzko-

224 Meier, 2017). The muscular insertion areas of AMI, AME and AMP were defined in the model in

225 order to apply the forces of muscular contraction during different prehension/bites. The direction

226 of these forces was defined by the line that joins the centroid of the insertion area in the skull

227 with its correspondence in the insertion area of the lower jaw. Following Alexander (1992), a

228 value of $0.3 \mathrm{MPa}$ was assumed as muscular contraction pressure. This resulted in applied muscle

229 forces of $229.7 \mathrm{~N}$ for the AMI, 1963.9 $\mathrm{N}$ for the AME and $685.2 \mathrm{~N}$ for the AMP. To simulate

230 biting, a fixed boundary condition in the three dimensions ( $\mathrm{x}, \mathrm{y}$ and $\mathrm{z}$ ) was applied in the bite

231 location to simulate the moment that skull and mandibles contact the prey.

232 For the lateral case, an arbitrary force of $100 \mathrm{~N}$ was applied in the z-direction at the position of

233 the fangs in the palate. Finally, for the skull-raising case, a muscular force was applied on the

234 cleidomastoideus muscle creating null displacement of the tip of the snout when the overall

235 weight of the skull is applied.

Thin sections - A histological study of cranial bones of Metoposaurus krasiejowensis

237 (UOPB 01029) has indicated a relatively stable collagen fibre pattern with parallel-fibred bone

238 constructing the grooves and inner cortex and lamellar bone present in the troughs/grooves of the

239 skull (Gruntmejer, Konietzko-Meier \& Bodzioch, 2016). In contrast, microstructural characters 
240 (thickness and compactness) change very clearly (Gruntmejer, Konietzko-Meier \& Bodzioch, 241 2016), and thus may be used as a proxy to estimate the mechanical loading. However, detailed

242 studies were not performed to analyse the relations between thicknesses, compactness and

243 estimated biomechanical loading. This is why these two features, based on the same thin section

244 collection as published by Gruntmejer, Konietzko-Meier \& Bodzioch (2016) are analysed here.

245 UOPB 01029 was sectioned in 16 places, inclusive of 17 flat dermal bones (Fig. 3; Table

246 1), according to standard petrographical procedures (Chinsamy \& Raath, 1992). Non-dermal

247 bones such as the exoccipital and quadratojugal were not analysed, because of their endochondral 248 origin and different shape. Subsequently, thin sections were studied under a LEICA DMLP light 249 microscope in normal and polarised light.

250 In the thin sections, the average thickness of the entire bone was estimated, expressed as 251 an arithmetical average from three measurements of the thickness of the entire bone. The average 252 thickness of the bone was measured three times over the distance between the ventral side of the 253 bone and the bottom of troughs/grooves, and three times as the distance to the top of ridges. The 254 mathematical average was calculated from these measurements.

255 To estimate bone porosity the thin sections were scanned using an Epson Scanner and 256 transformed into black and white images. The analysis of compactness was done using software 257 Bone Profiler (Girondot \& Laurin, 2003).

259 thickness, the significantly thinner parts of these bones (labelled in Figures and in the text as -b, 260 as opposed to the thicker part named -a), were calculated separately.

\section{RESULTS}




\section{Cranial biomechanics based on Finite Element Analysis}

265

266

267

268

269

270

271

272

273

274

275

276

277

278

279

280

281

282

283

284

285

286

287

Values of equivalent Von Mises stresses and their distribution were recorded in order to compare their behaviour under the effect of loads and constraints in the bilateral, unilateral, lateral biting and skull-raising for simulating feeding behaviour (see also Fortuny, Marcé-Nogué \& Konietzko-Meier, 2017).

Under bilateral biting, the model showed moderate to low-level stresses on most parts of the skull, with just a few peak stress levels in the posterior part (Fig. 4A). Small spots of stress were present on the dorsal portion of the supratemporal and posterior part of the squamosal, but mainly in ventral portions of the jugals and supratemporal and the posterior ramus of the pterygoid. Of particular interest is the absence of stress around the premaxilla, the posterior part of the maxilla and lacrimal and the naso-frontal region. Stress slightly increased around the orbits. On the palate, a few peak levels of stress were present near the choanae, with no levels of stress on the premaxilla, nor on most of the cultriform process and the parasphenoid.

Simulating unilateral biting reveals a different stress pattern for left and right parts of the skull with significantly higher levels of stress on the right side (Fig. 4B). The preorbital region presents moderate to high levels of stress in the region of anterior part of the right maxilla and increasing of loading in the interorbital region. An extremely high level of stress is reconstructed in the posterior part of the parietals and the postparietals as well as the otic notch (posterior part of the squamosal) up to the quadratojugal. The predicted stress level for the palate is even higher and refers to the quadratojugal-quadrate region and most of the pterygoid and is particularly high in the parasphenoid, and most of the cultriform process, as well as the exoccipitals (Fig. 4B).

The general pattern during lateral loading revealed low or absent levels of stress on the skull roof; on the quadratojugal stress was low (Fig. 4C). It is particularly significant that the antorbital region had extremely low levels of stress. However, on the palate, the general stress 
288 levels increase: low or moderate levels were seen on the vomer and premaxilla, while the

289 cultriform process presented low levels in its anterior part, moderate ones in its posterior part and

290 an absence from the central part. As far as the posterior part of the skull is concerned, high stress

291 levels were present on the posterior branch of the pterygoid and quadratojugals, while the anterior

292 part of the pterygoid had low or very low stress levels under lateral loading, while its central area

293 (adjacent to the parasphenoid) revealed moderate levels of stress. The major part of the

294 parasphenoid had moderate and high levels of stress, increasing on the posterior part of the

295 parasphenoid and in the exoccipitals.

296 The simulation of the skull raising system during jaw opening showed that the stress

297 values are very low along nearly the entire skull (Fig. 4D). The stress values increase only

298 significantly in the interorbital region, the regions around the otic notches, and the central part of

299 the cultriform process as well as posterior rami of the pterygoids (Fig. 4D). Lower, but still

300 measurable, stress is indicated in the anterior rami of the pterygoid, ectopterygoid and in the

301 vomer (Fig. 4D).

302

303 Biomechanical loading approach from thin section analysis

Bone microstructure-The average thickness of dermal bones varies from 2 to $10 \mathrm{~mm}$

305 (Table 1, Figs 5 and 6). In the posterior part of the skull, bones are the thickest (postparietal and

306 tabular), up to $10 \mathrm{~mm}$ and a compactness varying between 80 and $82 \%$. The microstructural

307 characters suggest a very high biomechanical loading on this part of the skull (Table 1; Fig. 5).

308 The postorbital and jugal represent a similar average thickness (close to $7 \mathrm{~mm}$ ), but the

309 compactness varies from 83 to $88 \%$, respectively (Table 1; Fig. 5) and thus the postorbital may

310 have been less loaded. However, bone microstructure predicts a lower loading, compared to the

311 posterior part of skull, but still both bones have high stress levels. Further decrease of the strength 
312 is observed for the lacrimal, quadratojugal, frontal and pterygoid bones, in which the thickness

313 oscillates around $6 \mathrm{~mm}$ and the compactness varies from 73 to $80 \%$ (Table 1; Figs 5 and 6). The

314 postfrontal, squamosal-1, squamosal-2-a, parietal and supratemporal-a present thicknesses of

315 around $4 \mathrm{~mm}$, with the compactness changing from 88 to 95\% (Table 1; Figs 5 and 6). The

316 postfrontal, squamosal-1, squamosal-2-a, parietal and supratemporal-a are thinner as lacrimal,

317 quadratojugal, frontal and pterygoid, but their compactness is considerably higher and for all

318 these bones a moderate stress level could be predicted (Table 1; Figs 5 and 6). The nasal,

319 prefrontal and parasphenoid-a with a relatively limited thickness and compactness received low

320 biomechanical loads (Table 1; Figs 5 and 6). The vomer is extremely porous, with a compactness

321 of only about $55 \%$, accompanied by limited thickness and possibly free of stress (Table 1, Figs 5

322 and 6). Markedly thinner and with a low load appear also medial parts of the supratemporal and

323 parasphenoid (in Figures 5 and 6 marked as -b) reaching about $2 \mathrm{~mm}$ of thickness, contrary to the

324 remaining parts (supratemporal-a and parasphenoid-a) with an average thickness of about $4 \mathrm{~mm}$

325 (Table 1, Figs 5 and 6). In squamosal-2 the change in bone thickness is more gradual (Fig. 5).

326 The supratemporal-b, parasphenoid-b and squamosal-2b are the thinnest among all bones, albeit

327 are extremely compact, over 90\% (Table 1; Figs 5 and 6).

To summarise, there is a linear relationship (Fig. 6) between compactness and average

329 bone thickness, with the only exception of vomer, being an outlier. Bones with high compactness

330 have low values of thickness and bones with low values of compactness have higher values of

331 thickness.

332 Cranial biomechanical loading approach from bone microstructure - The

333 microstructural bone characters suggest a high biomechanical resistance of the posterior part of

334 the skull; this is moderate in the preorbital and along the lateral edges of the skull roof, with a

335 tendency to decrease in the otic notch region and postorbital area (Fig. 6). A slight increase of 
336 biomechanical loading is present next to the posterior margin of the orbits (Fig. 6). The

337 squamosal-2-b which is the anterior part of this bone and a narrow valley that represents a lateral

338 canal in the supratemporal (supratemporal-b) are considerably weaker than the remaining part of

339 these bones (Fig. 6). Squamosal-2 shows a gradual increase in mechanical resistance in a

340 posterior direction, predicting slightly higher loading on the lateroposterior part (squamosal-2-a)

341 of the skull (Fig. 6). The postfrontal, squamosal-1, posterior part of squamosal-2 (squamosal-2-a),

342 parietal and supratemporal-a are thinner than the lacrimal, quadratojugal as well as frontal, but

343 significantly more compact and thus represent only a slight decrease of biomechanical strength.

344 With the same values in respect of thickness as in the prefrontal, nasal and parasphenoid-a, the

345 postfrontal, squamosal-1, squamosal-2-a, parietal and supratemporal-a are more compact and thus 346 able to resist higher stress (Fig. 6).

The microstructure of bones from the palatal side suggests moderate or low stress levels.

348 The vomer and the medial part of the parasphenoid (Fig. 6 - parasphenoid-b) appear to be 349 extremely weak, whereas the anterior branch of the pterygoid shows greater biomechanical 350 resistance.

DISCUSSION

New insights into skull biomechanics - merging methods

Bone histology vs computational biomechanics - how does bone structure correlate with Finite Element Analysis? - As a proxy to test predictions from FEA simulation, bone microstructure was used. In this context, very low levels of Von Mises stress appear in the thin and porous bones (vomer) and these levels increase when the compactness of the bone is higher and the thickness lower (parasphenoid-b, squamosal-2-b and supratemporal-b). As a general 
360 361

trend, high values of Von Mises stress appear in thicker bones, such as tabular, jugal or postorbital (Fig. 7).

The FEA results demonstrated that metoposaurids preferred rapid bilateral biting along with lateral strikes of the head, even if then latter behaviour was not preferred (Fortuny, MarcéNogué \& Konietzko-Meier, 2017). Based on FEA results, unilateral biting was avoided because the skull would experience a comparatively very high stress level, probably due to the absence of a secondary palate (Fortuny et al., 2016Fortuny, Marcé-Nogué \& Konietzko-Meier, 2017). The histological framework confirms a very close stress distribution pattern obtained during FE analyses (Fig. 7), including the fact that it was very far from optimal and not efficient for metoposaurs to perform unilateral biting in any scenario (Fig. 7A). The only case for which the histological model and unilateral FEA loading show the same tendency is a high loading present in the posterior part of skull (Fig. 7A) whereas under bilateral and lateral FEA loadings, this skull region receives a low or moderate level of stress (Fig. 7B and C). However, in this case the similar signal in unilateral and histological models is only a methodological artefact. The microstructural analysis reveals for the tabular and the postparietal that these elements are biomechanically adapted to receive high amounts of stress (Figs 5 and 6). Moreover, these bones are strongly metaplastic, which suggests a tight connection to muscles or ligaments (Gruntmejer, Konietzko-Meier \& Bodzioch, 2016). The reason for the presence of extremely resistant bones in this region is not directly connected with biting itself. A slight increase of stress level visible in the FEA model of skull raising (Fig. 7D) suggests that other variables, which are related directly to the mouth opening, affected the tabular and parotic process, otic notch and mainly the cleidomastoideus muscles and could explain the strength and biomechanical capabilities found in the histological analysis. 
The microstructural characters confirm that the nasal and prefrontal are relatively weak 384 bones; thus, the biomechanical loading in these regions was relatively low. In both simulations 385 (bilateral and lateral) the same tendency is observed, with a slight increase of stress level in the 386 prefrontal (Fig. 7B and C), which is also thinner (Fig. 5). In the frontal region, under a bilateral 387 case, the estimated stress level exceeded that in the prefrontal and nasal (Fig. 7B). Histologically, 388 the frontal is a relatively massive bone in comparison to the nasal and prefrontal. This indicates 389 that loading on the frontal region was probably high. The postfrontal, squamosal-2-a, parietal and squamosal-1 are thinner than the frontal, but more compact and thus the loading could be the 391 same or only slightly lower as on the frontal (Figs 5 and 6). The same tendency is observed in 392 bilateral and lateral FEA cases (Fig. 7B and C). Squamosal 2 is of special interest as the FE 393 models suggests a change of stress value from the posterior to the anterior part of this element, 394 receiving high to low levels, respectively (Fig. 7). Interestingly, the histological results also 395 reveal this change in the thickness of the cortex as well as in the porosity across the bone (Fig. 6). 396 Squamosal-2-b in both FEA cases (bilateral and lateral) show barely any stress anteriorly (Fig. 397 7B and C); moreover, histologically, squamosal-2-b is a very thin bone, indicating that the 398 mechanical loading of this part of skull was very low, only slightly increased posteriorly (Fig. 5). 399 As an entire bone, the supratemporal is adapted to moderate loading (Fig. 6), which is visible also 400 in bilateral and lateral FEA cases (Fig. 7). The histological framework of the supratemporal 401 suggests that the most sensitive part of this bone, which represents a drastically reduced strength, 402 is the lateral line canal (Fig. 6). The increase in bone compactness visible in the canal might 403 partially compensate a decrease of bone thickness in this place. The lamellar bone visible at the 404 bottom of the canal (Gruntmejer, Konietzko-Meier \& Bodzioch, 2016) is associated with marked 405 strength of this region but accompanied by low resistance in compression (Martin, 1991; Currey, 406 2003; Rhee et al., 2009; Achrai \& Wagner, 2013). The significant change of microstructural 
407 conditions, and thus biomechanical properties, shows that the lateral line canals might be crucial

408 structures for the biomechanical function of the skull; especially for metoposaurids with an

409 extremely deep system of lateral canals. The increased compactness of the bone on the bottom of

410 the canals might be an adaptation to preserve the optimal strength of the bone with minimal

411 thickness. However, it could have some side effect as compact bone is associated with a high

412 strength in tension (Martin, 1991; Currey, 2003; Rhee et al., 2009; Achrai \& Wagner, 2013), thus

413 lateral canals could serve as tensile members that are subjected to axial tensile forces occurring in

414 the skull.

415 The microstructure of the lacrimal, jugal and quadratojugal suggests a significantly high

416 loading on the lateral margins of the skull. The same tendency is visible in the lateral FEA case

417 (Fig. 7C), where an increase of stress level is suggested. It could be connected with the presence

418 of tooth rows on the ventral side of these bones. The histological results in this case suggest more

419 frequent occurrence of lateral biting than is concluded only from Finite Element Analysis.

With regard to the palatal side, the Finite Element loading cases suggest low stress for the

421 pterygoid and slightly higher for the parasphenoid, which is in agreement with the

422 microstructural results (Figs 6 and 7). Additionally, the histological framework suggests that the

423 parasphenoid was loaded closer to the external edges than near the central axis, where the bone is

424 thinnest. Marcé-Nogué et al. (2015) pointed out that during skull raising relatively high stress

425 affected the cultriform process. The histological results obtained herein do not appear to support

426 the idea of any high loading on the palatal side of the skull. However, the section was done only

427 from the very posterior part of the parasphenoid; the cultriform process itself was not sectioned.

428 Taking into account the high microstructural variability of skull bones (Gruntmejer, Konietzko-

429 Meier \& Bodzioch, 2016) it cannot be ruled out that the anterior part of this bone is highly

430 metaplastic. This, along with increased width of the process, might significantly increase the 
431 biomechanical strength of this bone. To confirm this hypothesis more sections are needed.

432 Otherwise, the Finite Element lateral case shows a stress increase in the vomer (Fig. 7C), but this

433 stress pattern is not supported by the histological framework, which suggests that the vomer is the 434 weakest bone of the entire skull (Fig. 6).

435 The exoccipital and quadratojugal have an endochondral origin and develop via a 436 cartilage precursor. Histologically, both bones resemble the structure of vertebrae with a highly 437 trabecular area surrounded by a thin cortex (Konietzko-Meier, Bodzioch \& Sander, 2013).

438 Between the trabeculae the remains of calcified cartilage are visible suggestings low ossification 439 of the endochondral region (Konietzko-Meier, Bodzioch \& Sander, 2013; Gruntmejer, Konietzko440 Meier \& Bodzioch, 2016). However, in both bones very strong Sharpey’s fibres are present 441 (Gruntmejer, Konietzko-Meier \& Bodzioch, 2016). Large concentrations of long, well442 mineralised Sharpey's fibres in the exoccipital appear to represent the remains of strong muscular 443 attachments and ligaments that connected the skull to the vertebral column that may have played 444 a role during skull raising.

446 New interpretation of mode of life

448 from several continents (Sulej, 2007). Despite their common occurrence and well-known 449 Bauplan, the mode of life of metoposaurids still remains controversial. In the past they were 450 either considered to have been passive bottom-dwellers in lakes and rivers, lying in wait for prey 451 using the passive "death-trap" model (Ochev, 1966; Murry, 1989), mid-water feeders, 452 comparable to temnospondyl capitosaurs (Howie, 1970; Chernin \& Cruickshank, 1978; Hunt, 453 1993) or active swimmers that used limbs (Sulej, 2007) or tail (Konietzko-Meier, Bodzioch \& 454 Sander, 2013) for propulsion. 
A 3D FEA of the metoposaur skull has thus revealed that the bottom dweller and active

456

457

458

459

460

461

462

463

464

465

predator hypotheses are the best supported ones (Fortuny, Marcé-Nogué \& Konietzko-Meier, 2017). Metoposaurids preferred rapid bilateral biting, which according to the present study, would confirm the ambush strategy - resting on the bottom in wait for passing prey. The relatively low stress level found along the skull under lateral strike indicates that lateral strike of the head was possible, even if this was not preferred and connected with active predatory activity (Fortuny, Marcé-Nogué \& Konietzko-Meier, 2017). However, as mentioned above, the FEA analysis has a limitation concerning the number of tested scenarios. Merging two different approaches (Finite Element Analysis and bone histology) provides data from different perspectives on skull biomechanics that, when correlated, yield a clearer image of the feeding behaviour of Metoposaurus. This genus appears to have comprised aquatic animals that could adapt to various environmental conditions and were less specialised in their mode of feeding than assumed previously (Ochev, 1966; Murry, 1989; Howie, 1970; Chernin \& Cruickshank, 1978; Hunt, 1993; Sulej, 2007). Histological results confirm the presence of direct lateral and bilateral biting, but do not exclude other combinations, with the exception of unilateral biting, and may reinforce the idea that lateral strike was also performed under an ambush strategy and not only during active swimming. It cannot be ruled out that once the prey was captured by a lateral strike, a bilateral bite was required to immobilise it, as suggested for extant giant salamanders (Fortuny et al., 2015).

Bone microstructure indicates a significantly high loading on the lateral margins of the skull, suggesting a more frequent occurrence of lateral biting than is concluded from the Finite Element Analysis only (Fig. 7). The main biting forces are connected with long rows of teeth along the skull margin. These rows occlude with the tooth row in the dentary, which is supported by the presence of sharp cutting edges on the tooth margin in dentary teeth (Konietzko-Meier \& 
479 Wawro, 2007). Crucial is the role of the vomer tusk. As histology reveals, the vomer is a very 480 weak bone; on the basis of FEA, there was stress increase in the vomer during lateral biting, but 481 this was absent under bilateral biting. At first view, this is contradictory. However, it may 482 indicate that the vomer tusks only played an active role in bilateral biting, but not in lateral biting 483 because they could easily have snapped.

The main factor that determines the mode of life may be water level. The two-season 485 climate during the Late Triassic, with high and low water levels in local lakes and periodic rivers 486 (Bodzioch \& Kowal-Linka, 2012) requires changing ecological strategies to survive the 487 unfavourable dry season. Among amphibians, the common strategy is to wait out the dry or cold 488 season (aestivation/hibernation). However, the growth pattern preserved in long bones (revealed 489 by histology) of Metoposaurus does not show distinct, seasonal Lines of Arrested Growth 490 (LAGs) at all, but only zones and unusually thick annuli, which point to a reduced growth rate for a certain period (Konietzko-Meier \& Klein, 2013; Konietzko-Meier \& Sander, 2013). The

492 numerous lines present in annulus indicate that animals reduced their activity for several short periods but did not aestivate for the entire unfavourable interval (Konietzko-Meier \& Klein, 2013;

494 Konietzko-Meier \& Sander, 2013). Growth, even slow, requires a regular access to energy.

495 Because of seasonally variable high and low water levels, feeding strategies had to be adequate to 496 counter environmental conditions. During favourable water conditions metoposaurids may have 497 been ambush and active predators capable of lateral strikes of the head. The dry season may have 498 required a less active mode of life with particularly efficient bilateral biting, together with their 499 characteristically anteropositioned orbits, optimal for ambush strategy. 501 genus Apachesaurus from North America (Fortuny, Marcé-Nogué \& Konietzko-Meier, 2017, but 502 see Gee, Parker \& Marsh, 2017, for a discussion of the validity of the genus). Overall it could be 
503 concluded that metoposaurids were well adapted for survival under various conditions, yet not

504 specialised as far as feeding strategies were concerned. This ability to acquire food independently

505 of environmental conditions could be the key character in explaining the very common

506 occurrence of metoposaurids during the Late Triassic. However, the question remains why, in

507 spite of their wide adaptive strategies, they disappeared, together with other temnospondyl

508 groups, at the end of the Late Triassic. Milner $(1993,1994)$ documented the demise of

509 capitosaurids, metoposaurids and latiscopids at the Norian-Rhaetian boundary as part of the end-

510 Triassic extinction event (ETE), considered to rank amongst the 'Big Five' mass extinctions.

511 Global changes in environmental and ecological conditions may have surpassed the adaptive

512 capabilities for metoposaurids.

513

CONCLUSIONS

1. A histological analysis of skull microstructure mostly confirms the models created by FEA, with exception of the vomer which, histologically speaking, is a low-loaded bone, but on the basis of FEA, there is stress increase in the vomer during lateral biting (absent under bilateral biting). Also a significant change of microstructural conditions, and thus biomechanical properties, shows that the lateral line canals might be crucial structures for the biomechanical function of the skull, especially for metoposaurids with an extremely deep system of lateral canals; this should be considered in the FEA modelling. The merging of histological studies and FEA confirm that the 'negative' scenario (in this case unilateral biting) was correctly indicated by FEA. However, the limited number of tested scenarios may erroneously interpret 'positive' behaviours and may lead to serious simplifications. 
2. Metoposaurus was an aquatic animal that could adapt to various environmental conditions and was unspecialised in its mode of feeding. It may have used two foraging techniques in hunting; bilateral biting, as well as lateral strikes, and active hunting using lateral strikes of the head.

3. One of the potential main factors determining the mode of life may have been water level. During favourable water conditions metoposaurids may have been ambush and active predators capable of lateral strikes of the head. The dry season required a less active mode of life with particularly efficient bilateral biting; coupled with their characteristically anteropositioned orbits, this would have been optimally suited for an ambush strategy.

\section{ACKNOWLEDGEMENTS}

We thank Hospital Mutua de Terrassa (Catalonia, Spain) for CT scanning of one of the specimens. Caio Souto Maior (UPC) is acknowledged for his help with segmentation of the Metoposaurus specimen.We are grateful to John W.M. Jagt (Natuurhistorisch Museum Maastricht, the Netherlands) for improving the English. D.K.-M. thanks Martin Sander for fruitful discussion and support. The journal editor (Claudia Marsicano) and reviewers (Stephan Lautenschlager and two anonymous) are acknowledged for their comments which improved an earlier typescript significantly.

Achrai B, Wagner HD. 2013. Micro-structure and mechanical properties of the turtle carapace as a biological composite shield. Acta Biomaterialia 9: 5890-5902. 
549 550

551

552

553

554

555

556

557

558

559

560

561

562

563

564

565

566

567

568

569

570

571

572

Alexander RM. 1992. Exploring biomechanics: animals in motion. 2nd edn. W.H. Freeman, New York.

Anderson PSL, Bright JA, Gill PG, Rayfield EJ. 2012. Models in palaeontological functional analysis. Biology Letters 8: 119-122.

Barycka E. 2007. Morphology and ontogeny of the humerus of the Triassic temnospondyl amphibian Metoposaurus diagnosticus. Neues Jahrbuch für Geologie und Paläontologie Abhandlungen 243: 351-361.

Biewener AA. 1993. Safety factors in bone strength. Calcified Tissue International and Musculoskeletal Research 53:68-74.

Bodzioch A, Kowal-Linka M. 2012. Unraveling the origin of the Late Triassic multitaxic bone accumulation at Krasiejów (S Poland) by diagenetic analysis. Palaeogeography, Palaeoclimatology, Palaecology 346/347: 25-36.

Bright JA, Rayfield EJ. 2011. Sensitivity and ex vivo validation of finite element models of the domestic pig cranium. Journal of Anatomy 219:456-471.

Bright JA. 2012. The importance of craniofacial sutures in biomechanical finite element models of the domestic pig. PLoS One 7: e31769.

Bright JA. 2014. A review of paleontological Finite Element models and their validity. Journal of Paleontology 88: 760-769.

Carrier D, Leon LR.1990. Skeletal growth and function in the California gull (Larus californicus). Journal of Zoology 222: 375-389.

Carroll RL, Holmes R. 1980. The skull and jaw musculature as guides to the ancestry salamanders. Zoological Journal of the Linnean Society 68: 1-40.

Chernin S, Cruickshank ARI. 1978. The myth of the bottom-dwelling capitosaur amphibians. South African Journal of Science 74: 111-112. 
573 Chinsamy A, Raath MA. 1992. Preparation of fossil bone for histological examination.

574

575

576

577

578

579

580

581

582

583

584

585

586

587

588

589

590

591

592

593

594
Palaeontologia Africana 29: 39-44.

Cox PG, Fagan MJ, Rayfield EJ, Jeffery N. 2011. Finite element modelling of squirrel, guinea pig and rat skulls: using geometric morphometrics to assess sensitivity. Journal of Anatomy 219: 696-709.

Currey JD. 1987. The evolution of the mechanical properties of amniote bone. Journal of Biomechanics 20: 1035-1044.

Currey JD. 2003. The many adaptations of bone. Journal of Biomechanics 36: 1487-1495.

Currey JD. 2006. Bones: structure and mechanics. Princeton University Press, Princeton, NJ.

Currey JD. 2012. The structure and mechanics of bone. Journal of Materials Science 47: 41-54.

Currey JD, Pitchford JW, Baxter PD. 2007. Variability of the mechanical properties of bone, and its evolutionary consequences. Journal of the Royal Society Interface 4: 127-135.

Damiani R, Schoch RR, Hellrung H, Werneburg R, Gastou S. 2009. The plagiosaurid temnospondyl Plagiosuchus pustuliferus (Amphibia: Temnospondyli) from the Middle Triassic of Germany: anatomy and functional morphology of the skull. Zoological Journal of the Linnean Society 155: 348-373.

Fitton LC, Shi JF, Fagan MJ, O’Higgins P. 2012. Masticatory loadings and cranial deformation in Macaca fascicularis, a finite element analysis sensitivity study. Journal of Anatomy 221: $55-68$.

Fortuny J, Marcé-Nogué J, de Esteban-Trivigno S, Gil L, Galobart Á. 2011. Temnospondyli bite club: ecomorphological patterns of the most diverse group of early tetrapods. Journal of Evolutionary Biology 24: 2040-2054. 
595 Fortuny J, Marcé-Nogué J, Gil L, Galobart Á. 2012. Skull mechanics and the evolutionary

596

597

598

599

600

601

602

603

604

605

606

607

608

609

610

611

612

613

614

615

616

617

618

patterns of the otic notch closure in capitosaurs (Amphibia: Temnospondyli). The Anatomical Record 295: 1134-1146.

Fortuny J, Marcé-Nogué J, Heiss E, Sanchez M, Gil L, Galobart À. 2015. 3D bite modeling and feeding mechanics of the largest living amphibian, the Chinese giant salamander Andrias davidianus (Amphibia: Urodela). PLoS ONE 10: e0121885.

Fortuny J, Marcè-Noguè J, Steyer JS, De Esteban-Trivigno S, Mujal E, Gil L. 2016.

Comparative 3D analyses and palaeoecology of giant early amphibians (Temnospondyli: Stereospondyli). Scientific Reports 6: 30387.

Fortuny J, Marcè-Noguè J, Konietzko-Meier D. 2017. Feeding biomechanics of Late Triassic metoposaurids (Amphibia: Temnospondyli): a 3D finite element analysis approach. Journal of Anatomy 230: 752-765.

Gee BM, Parker WG, Marsh AD. 2017. Microanatomy and paleohistology of the intercentra of North American metoposaurids from the Upper Triassic of Petrified Forest National Park (Arizona, USA) with implications for the taxonomy and ontogeny of the group. PeerJ 5: e3183.

Girondot M, Laurin M. 2003. Bone Profiler: a tool to quantify, model, and statistically compare bone-section compactness profiles. Journal of Vertebrate Paleontology 23: 458-461.

Gruntmejer K, Konietzko-Meier D, Bodzioch A. 2016. Cranial bone histology of Metoposaurus krasiejowensis (Amphibia, Temnospondyli) from the Late Triassic of Poland. PeerJ 4: e2685.

Haines RW, Mohuiddin A. 1968. Metaplastic bone. Journal of Anatomy 103: 527-538.

Holmes RB, Carroll RL. 1977. A temnospondyl amphibian from the Mississippian of Scotland. Bulletin of the Museum of Comparative Zoology 147: 489-511. 
619 Howie AA. 1970. A new capitosaurid labyrinthodont from East Africa. Palaeontology 13: 210-

620

621

622

623

624

625

626

627

628

629

630

631

632

633

634

635

636

637

638

639

640

641

642

253.

Hunt AP. 1993. Revision of the Metoposauridae (Amphibia, Temnospondyli) and description of a new genus from western North America. In: Aspects of Mesozoic geology and paleontology of the Colorado Plateau (ed. M. Morales), pp. 67-97. Museum of Northern Arizona Bulletin 59.

Konietzko-Meier D, Bodzioch A, Sander PM. 2013. Histological characteristics of the vertebral intercentra of Metoposaurus diagnosticus (Temnospondyli) from the Upper Triassic of Krasiejów (Upper Silesia, Poland). Earth and Environmental Science, Transactions of the Royal Society of Edinburgh 103: 1-14.

Konietzko-Meier D, Klein N. 2013. Unique growth pattern of Metoposaurus diagnosticus krasiejowensis (Amphibia, Temnospondyli) from the Upper Triassic of Krasiejów, Poland. Palaeogeography, Palaeoclimatology, Palaeoecology 370: 145-157.

Konietzko-Meier D, Sander PM. 2013. Long bone histology of Metoposaurus diagnosticus (Temnospondyli) from the Late Triassic of Krasiejów (Poland) and its paleobiological implications. Journal of Vertebrate Paleontology 35: 1-16.

Konietzko-Meier D, Wawro K. 2007. Mandibular dentition in the Late Triassic temnospondyl amphibian Metoposaurus. Acta Palaeontologia Polonica 52: 213-215.

Kupczik K, Dobson CA, Fagan MJ, Crompton RH, Oxnard CE, O’Higgins P. 2007. Assessing mechanical function of the zygomatic region in macaques: validation and sensitivity testing of finite element models. Journal of Anatomy 210: 41-53.

Lautenschlager S, Witzmann F, Werneburg I. 2016. Palate anatomy and morphofunctional aspects of interpterygoid vacuities in temnospondyl cranial evolution. The Science of Nature 103: 79. 
643 Maganuco S, Steyer JS, Pasini G, Boulay M, Lorrain S, Bénéteau A. 2009. An exquisite

644

645

646

647

648

649

650

651

652

653

654

655

656

657

658

659

660

661

662

663

664

665

specimen of Edingerella madagascarensis (Temnospondyli) from the Lower Triassic of NW Madagascar; cranial anatomy, phylogeny, and restorations. Memorie della Società italiana di Scienze naturali di Milano 36: 1-72.

Marcé-Nogué J, Fortuny J, De Esteban-Trivigno S, Sánchez M, Gil L, Galobart À. 2015. 3D computational mechanics elucidate the evolutionary implications of orbit position and size diversity of early amphibians. PLoS One 10: e0131320.

Margerie E, Robin JP, Verrier D, Cubo J, Groscolas R, Castanet J. 2004. Assessing a relationship between bone microstructure and growth rate: a fluorescent labelling study in the king penguin chick (Aptenodytes patagonicus). Journal of Experimental Biology 207: 869879.

Martin RB. 1991. Determinants of the mechanical properties of bones. Journal of Biomechanics 24: 79-88.

McCurry MR, Evans AR, McHenry CR. 2015. The sensitivity of biological finite element models to the resolution of surface geometry: a case study of crocodilian crania. PeerJ 3: e988.

Milner AR. 1990. The radiations of temnospondyl amphibians. In: Major evolutionary radiations (eds P. D. Taylor and G. P. Larwood), pp. 321-334. Clarendon Press, Oxford.

Milner AR. 1993. Biogeography of Palaeozoic tetrapods. In: Palaeozoic vertebrate biostratigraphy and biogeography (ed. J. A. Long), pp. 324-353. Belhaven Press, London.

Milner AR. 1994. Late Triassic and Jurassic amphibians: fossil record and phylogeny. In: In the shadow of the dinosaurs: early Mesozoic tetrapods (eds N. C. Fraser and H. D. Sues), pp. 5-22. Cambridge University Press, Cambridge. 
Milner AR, Sequeira SEK. 1998. A cochleosaurid temnospondyl amphibian from the Middle Pennsylvanian of Linton, Ohio, U.S.A. Zoological Journal of the Linnean Society 122: $261-290$.

Mishra S. 2009. Biomechanical aspects of bone microstructure in vertebrates: potential approach to palaeontological investigations. Journal of Biosciences 34: 799-809.

Murry PA. 1989. Geology and paleontology of the Dockum Formation (Upper Triassic), west Texas and eastern New Mexico. In: Dawn of the age of dinosaurs in the American Southwest (eds S. G. Lucas and A. P. Hunt), pp. 102-144. Museum of Natural History, Albuquerque, New Mexico.

Ochev VG. 1966. Systematics and phylogeny of capitosauroid labyrinthodonts. Saratov State University Press, Saratov [in Russian].

Racki G, Szulc J. 2015. The bone-bearing Upper Triassic of Upper Silesia, southern Poland: integrated stratigraphy, facies and events - introductory remarks. Annales Societatis Geologorum Poloniae 85: 553-555.

Rayfield EJ. 2007. Finite Element Analysis and understanding the biomechanics and evolution of living and fossil organisms. Annual Review of Earth and Planetary Sciences 35: 541-576.

Rhee H, Horstemeyer MF, Hwang Y, Lim H, Kadiri HE, Trim W. 2009. A study on the structure and mechanical behavior of the Terrapene Carolina carapace: a pathway to design bioinspired synthetic composites. Materials Science and Engineering C29: 2333-2339.

Rinehart LF, Lucas SG. 2013. The functional morphology of dermal bone ornamentation in temnospondyl amphibian. In: The Triassic System (eds L. H. Tanner, J.A. Spielmann and S.G. Lucas), pp. 524-532. New Mexico Museum of Natural History and Science, Bulletin 61. 
689 Ross CF, Patel BA, Slice DE, Strait DS, Dechow PC, Richmond BG, Spencer MA. 2005.

690

691

692

693 Modeling masticatory muscle force in finite element analysis: sensitivity analysis using principal coordinates analysis. The Anatomical Record, Part A. Discoveries in molecular cellular and evolutionary biology 283A: 288-299.

Sanchez S, Germain D, Ricqlès A de, Abourachid A, Goussard F, Tafforeau P. 2010. Limb-bone histology of temnospondyls: implications for understanding the diversification of palaeoecologies and patterns of locomotion of Permo-Triassic tetrapods. Journal of Evolutionary Biology 3: 2076-2090.

Schoch RR. 2013. The evolution of major temnospondyl clades: an inclusive phylogenetic analysis. Journal of Systematic Palaeontology 11: 673-705.

Stayton CT, Ruta M. 2006. Geometric morphometrics of the skull roof of stereospondyls (Amphibia: Temnospondyli). Palaeontology 49: 307-337.

Steyer JS, Damiani R, Sidor CA, O’Keefe, FR, Larsson HCE, Maga A, Oumarou I. 2006. The vertebrate fauna of the Upper Permian of Niger. IV. Nigerpeton ricqlesi (Temnospondyli: Cochleosauridae), and the Edopoid colonization of Gondwana. Journal of Vertebrate Paleontology 26: 18-28.

Steyer JS, Boulay M, Lorrain S. 2010. 3D external restorations of stegocephalian skulls using Zbrush: the renaissance of fossil amphibians. Comptes Rendus Palevol 9: 463-470.

Sulej T. 2002. Species discrimination of the Late Triassic temnospondyl amphibian Metoposaurus diagnosticus. Acta Palaeontologica Polonica 47: 535-546.

Sulej T. 2007. Osteology, variability, and evolution of Metoposaurus, a temnospondyl from the Late Triassic of Poland. Palaeontologia Polonica 64: 29-139.

Szulc J, Racki G, Jewuła K. 2015. Key aspects of the stratigraphy of the Upper Silesian middle Keuper, southern Poland. Annales Societatis Geologorum Poloniae 85: 557-586. 
713 Szulc J, Racki G, Jewuła K, Środoń A. 2015b. How many Upper Triassic bone-bearing levels are

714

715

716

717

718

719

720

721

722

723

724

725

726

727

728

729

730

731

732

733

734

735

736 there in Upper Silesia (southern Poland)? A critical overview of stratigraphy and facies. Annales Societatis Geologorum Poloniae 85: 587-626.

Teschner EM, Sander PM, Konietzko-Meier D. 2017. Variability of growth pattern observed in Metoposaurus krasiejowensis humeri and its biological meaning. Journal of Iberian Geology doi: 10.1007/s41513-017-0038-y.

Walmsley CW, McCurry MR, Clausen PD, McHenry CR. 2013. Beware of the black box: investigating the sensitivity of FEA simulations to modelling factors in comparative biomechanics. PeerJ 1: e204.

Wang Q, Smith AL, Strait DS, Wright BW, Richmond BG, Grosse IR, Byron CD, Zapata U. 2010. The global impact of sutures assessed in a finite element model of a macaque cranium. The Anatomical Record 293: 1477-1491.

Wang Q, Wood SA, Grosse IR, Ross CF, Zapata U, Byron CD, Wright BW, Strait DS. 2012. The role of sutures in biomechanical dynamic simulation of a macaque cranial finite element model: implications for the evolution of craniofacial form. The Anatomical Record 295: $278-288$.

Warren AA. 2000. Secondarily aquatic temnospondyls of the Upper Permian and Mesozoic. In: Volume 4 (eds H. Heatwole and R. L. Carroll), pp. 1121-1149. Beatty \& Sons, Chipping Norton.

Warren A, Rich T, Vickers-Rich PV. 1997. The last labyrinthodonts? Palaeontographica Abteilung A 247: 1-24.

Witzel U, Mannhardt J, Goessling R, de Micheli P, Preuschoft H. 2011. Finite Element Analyses and virtual syntheses of biological structures and their application to sauropod skulls. In: Biology of sauropod dinosaurs. Understanding the life of giants (eds N. Klein, K. Remes, 
737 738

739 740

741

742 743
C. T. Gee and P. M. Sander), pp. 171-196. Indiana University Press, Bloomington/Indianapolis.

Witzmann F. 2006. Cranial morphology and ontogeny of the Permo-Carboniferous temnospondyl Archegosaurus decheni Goldfuss, 1847 from the Saar-Nahe Basin, Germany. Earth and Environmental Science, Transactions of the Royal Society of Edinburgh 96: 131-162.

Witzmann F. 2009. Comparative histology of sculptured dermal bones in basal tetrapods, and the implications for the soft tissue dermis. Palaeodiversity 2: 233-270.

Witzmann F, Schoch RR. 2013. Reconstruction of cranial and hyobranchial muscles in the Triassic temnospondyl Gerrothorax provides evidence for akinetic suction feeding. Journal of Morphology 274: 525-542.

Wood SA, Strait DS, Dumont ER, Ross CF, Grosse IR. 2011. The effect of modeling simplifications on craniofacial finite element models: the alveoli (tooth sockets) and periodontal ligaments. Journal of Biomechanics 44: 1831-1838.

Zioupos P, Hansen U, Currey JD. 2008. Microcracking damage and the fracture process in relation to strain rate in human cortical bone tensile failure. Journal of Biomechanics 41: $2932-2939$. 
$761 \quad$ Figure captions

762

763 Figure 1 Skull of Metoposaurus krasiejowensis from the Upper Triassic of southwest Poland 764 (UOPB 01029) used in the histological study, in dorsal (A) and palatal (B) views. Scale bar 765 equals $10 \mathrm{~cm}$.

766

767 Figure 2 Loading and boundary conditions used to simulate (A) bilateral and unilateral biting, 768 (B) lateral biting, and (C) skull-raising system. Coloured areas indicate muscle insertion areas 769 (AME, AMI, AMP and Cleidomastoideus, respectively). Arrows indicate the direction of the 770 muscle force applied. ImageCredit: Journal of Anatomy/Wiley.

771

772 Figure 3 Sectioning planes of dermal bones of skull of Metoposaurus krasiejowensis (UOPB 773 01029) in dorsal (A) and palatal (B) views. Scale bar equals $10 \mathrm{~cm}$. Abbreviations: f, frontal; j, 774 jugal; 1, lacrimal; n, nasal; p, parietal; pf, postfrontal; po, postorbital; pp, postparietal; prf, 775 prefrontal; ps, parasphenoid; pt, pterygoid; qj, quadratojugal; sq1, squamosal-1; sq2, squamosal$776 \quad 2$; st, supratemporal; t, tabular; v, vomer.

777

778 Figure 4 Von Mises stress results (in $\mathrm{MPa}$ ) of bilateral (A), unilateral biting (B), lateral (C) and 779 of skull raising system (D) in Metoposaurus krasiejowensis (UOPB 00124) using a gape angle of $78010^{\circ}$. ImageCredit: Journal of Anatomy/Wiley.

Figure 5 General microstructure of skull bones in Metoposaurus krasiejowensis (UOPB 01029).

783 All bones are shown in the same scale, whereas the skull miniatures are included only to show 784 the position of bones and are not in scale. Scale bar equals $10 \mathrm{~mm}$. 
786 Figure 6 Estimated biomechanical loading as reconstructed on the basis of microstructural 787 characters of the skull of Metoposaurus krasiejowensis (UOPB 01029). Note that the estimated 788 values (average bone thickness vs compactness) are relative and show merely if loading on any 789 given region was higher or lower (on the scale bar from red to blue, respectively). It is not 790 possible to calculate the objective amount of stress in this case. Black bars inside colour ellipses 791 indicate the sectioning places; the ellipses without bars are symmetrical to sectioned areas.

793 Figure 7 Von Mises stress results merged with the model of biomechanical loading created on 794 the basis of microstructural characters. Von Mises stress results represent unilateral (A), bilateral 795 (B), lateral (C) biting and of skull-raising system (D) in Metoposaurus krasiejowensis (UOPB 796 00124) using a gape angle of $10^{\circ}$. Model of biomechanical loading is created on the basis of 797 microstructural characters for skull UOPB 01029. Skulls in the background show FEA results; 798 the outcome of histological reconstructions is illustrated as oval forms, of different colours. Note 799 that similar colours were used in FEA analysis and histological estimates in order to illustrate 800 how the general stress distribution in FEA and histological analyses correlate; however, identical 801 colours do not signify identical stress values. In FEA, the colours refer to objective values 802 (compare with Figure 4), while in histological models estimated values are relative and show 803 merely if the loading on any given region is higher or lower within a single skull (on the scale bar

804 from red to blue, which means from high to low loading, respectively). Black bars inside colour 805 ellipses indicate the sectioning places; the ellipses without bars are symmetrical to section areas. 806 The black dotted lines shows the sutures, the red lines indicate the reconstructed borders. 


\section{Table $\mathbf{1}$ (on next page)}

The thickness and compactness of the dermal skull bones of Metoposaurus krasiejowensis from Late Triassic of Poland.

${ }^{1}$ The average thickness of entire bone was estimated in thin sections, expressed as an arithmetical average from three measurements of the thickness of a bone taken on the bottom of valleys and the top of ridges; ${ }^{2}$ Compactness was estimated using the software Bone Profiler (Girondot and Laurin, 2003). 
1 Table 1. The thickness and compactness of the dermal skull bones of Metoposaurus

2 krasiejowensis from Late Triassic of Poland.

\begin{tabular}{|c|c|c|}
\hline bone & average thickness $(\mu \mathrm{m})^{1}$ & compactness $(\%)^{2}$ \\
\hline nasal & 4758 & 77.4 \\
\hline prefrontal & 4256 & 78.5 \\
\hline lacrimal & 5940 & 79.2 \\
\hline frontal & 5549 & 76.3 \\
\hline postfrontal & 3960 & 94.5 \\
\hline jugal & 6940 & 87.8 \\
\hline postorbital & 6940 & 82.6 \\
\hline parietal & 3840 & 92.2 \\
\hline supratemporal-a & 4800 & 92.5 \\
\hline supratemporal-b & 2050 & 98.6 \\
\hline squamosal-1 & 3915 & 89.1 \\
\hline squamosal-2-a & 4000 & 94.0 \\
\hline squamosal-2-b & 1600 & 98.7 \\
\hline quadratojugal & 5610 & 78.6 \\
\hline postparietal & 8670 & 80.7 \\
\hline tabular & 10000 & 82.5 \\
\hline vomer & 2925 & 54.7 \\
\hline parasphenoid-a & 4050 & 77.7 \\
\hline parasphenoid-b & 2100 & 91.0 \\
\hline pterygoid & 5460 & 73.1 \\
\hline
\end{tabular}

3

$4{ }^{1}$ The average thickness of entire bone was estimated in thin sections, expressed as an arithmetical

5 average from three measurements of the thickness of a bone taken on the bottom of valleys and

6 the top of ridges; ${ }^{2}$ Compactness was estimated using the software Bone Profiler (Girondot and

7 Laurin, 2003). 
Figure 1

Skull of Metoposaurus krasiejowensis from the Upper Triassic of southwest Poland (UOPB 01029) used in the histological study, in dorsal (A) and palatal (B) views.

Scale bar equals $10 \mathrm{~cm}$.
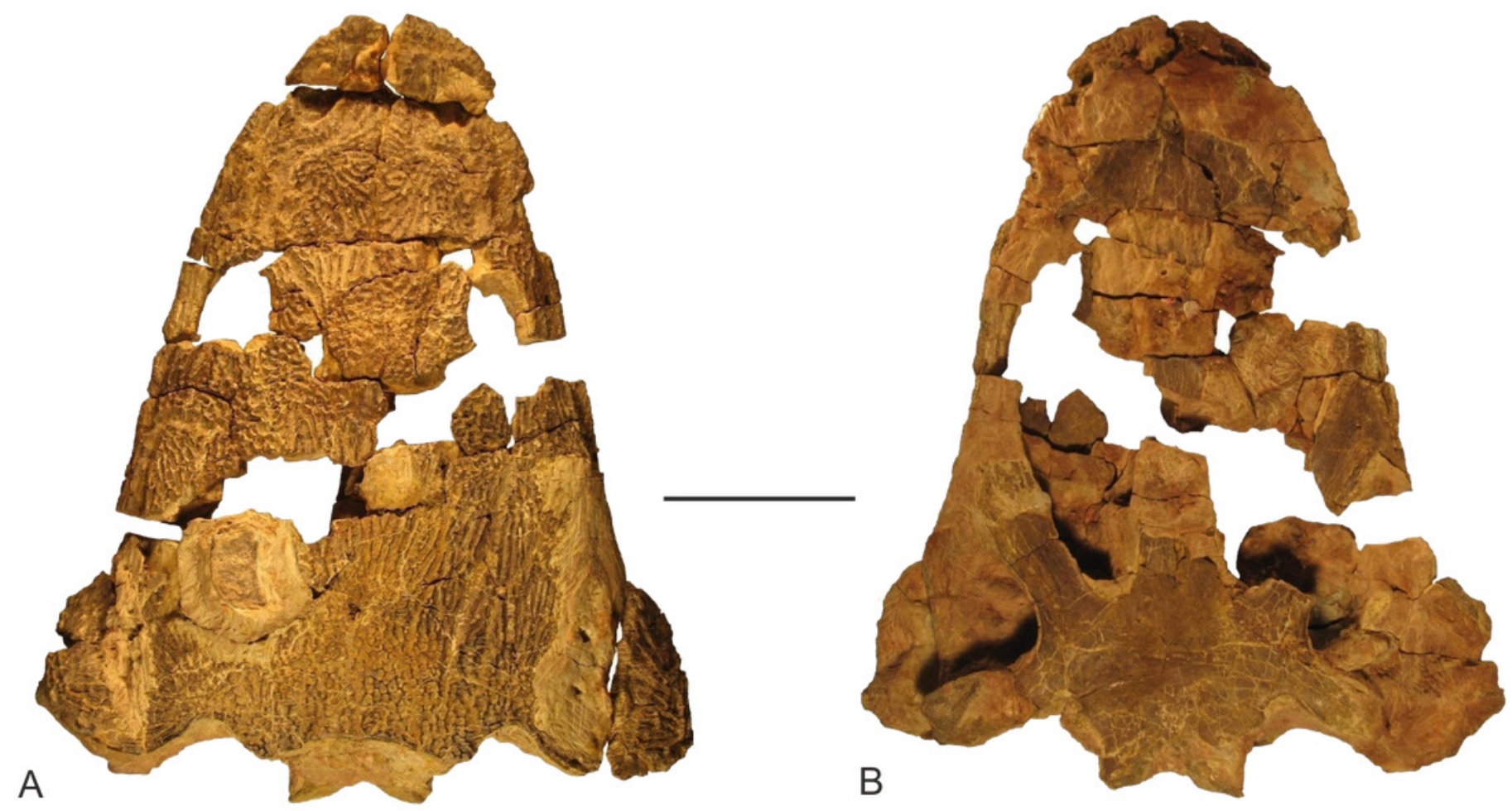


\section{Figure 2}

Loading and boundary conditions used to simulate $(A)$ bilateral and unilateral biting, $(B)$ lateral biting, and (C) skull-raising system.

Coloured areas indicate muscle insertion areas (AME, AMI, AMP and Cleidomastoideus, respectively). Arrows indicate the direction of the muscle force applied. ImageCredit: Journal of Anatomy/Wiley.

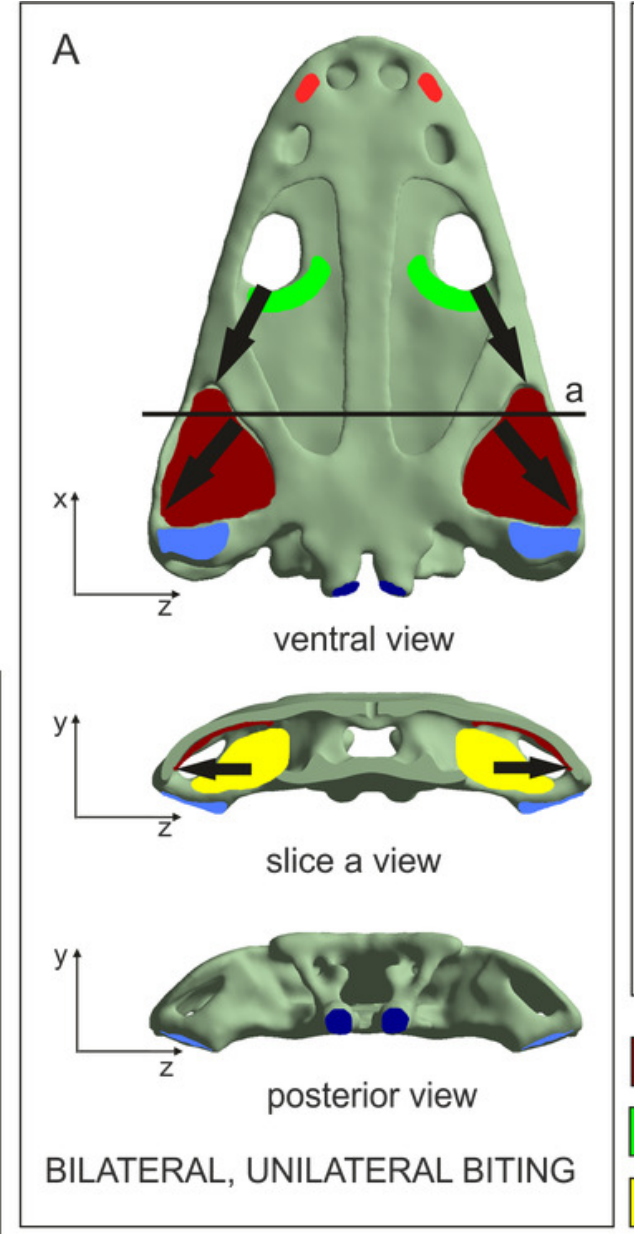

Condyle Fixed Boundary Condition

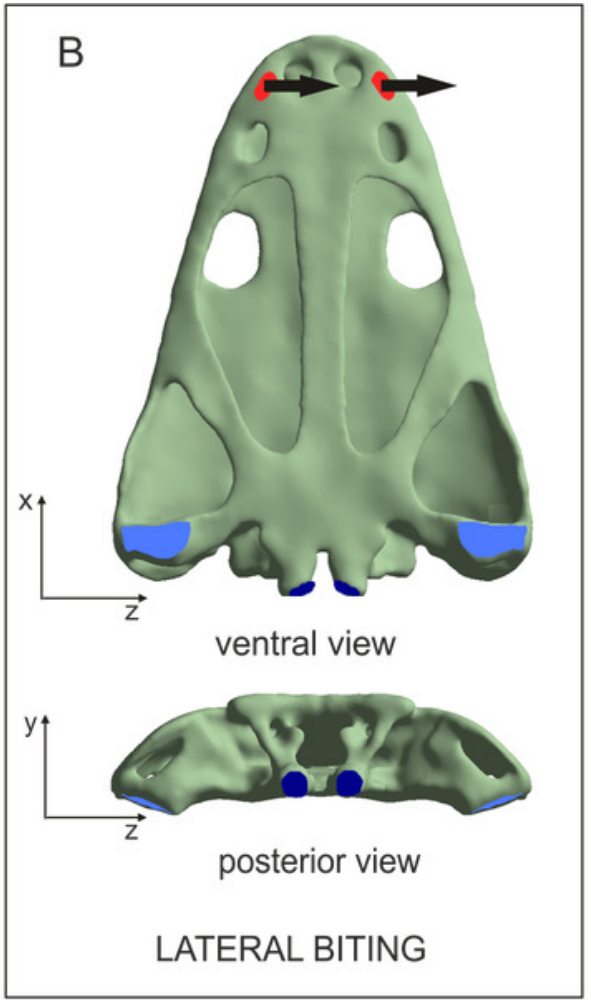

Adductor Mandibulae Externus (AME) Adductor Mandibulae Internus (AMI) Adductor Mandibulae Posterior (AMP) Jaw Joint Fixed Boundary Condition

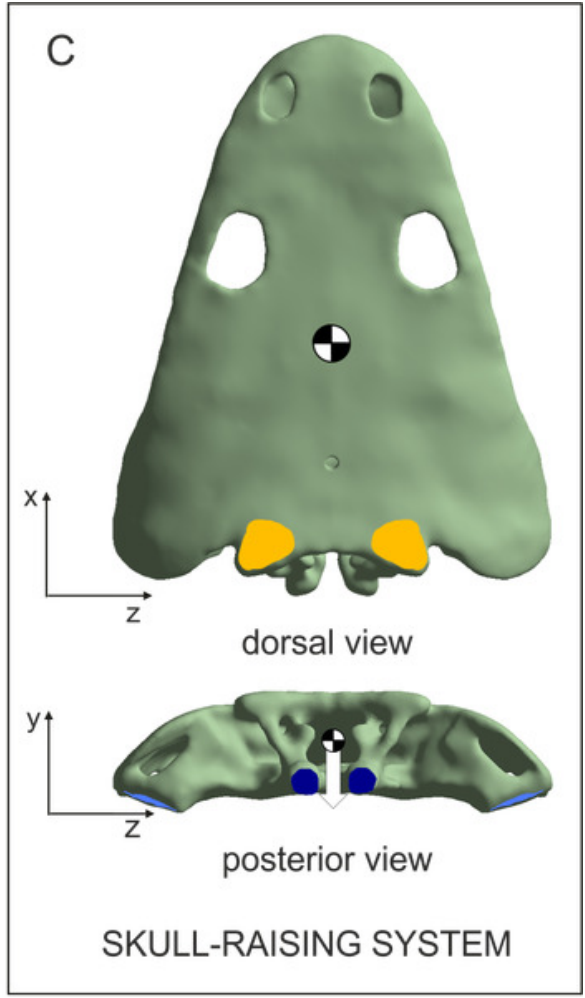

Bite Fixed Boundary Condition

TBite Lateral Loading

Cleidomastoideus

Self-Weight $\oplus$ Center of Mass 


\section{Figure 3}

Sectioning planes of dermal bones of skull of Metoposaurus krasiejowensis (UOPB 01029) in dorsal (A) and palatal (B) views.

Scale bar equals $10 \mathrm{~cm}$. Abbreviations: f, frontal; j, jugal; I, lacrimal; $n$, nasal; $p$, parietal; pf, postfrontal; po, postorbital; pp, postparietal; prf, prefrontal; ps, parasphenoid; pt, pterygoid; qj, quadratojugal; sq1, squamosal-1; sq2, squamosal-2; st, supratemporal; t, tabular; v, vomer.
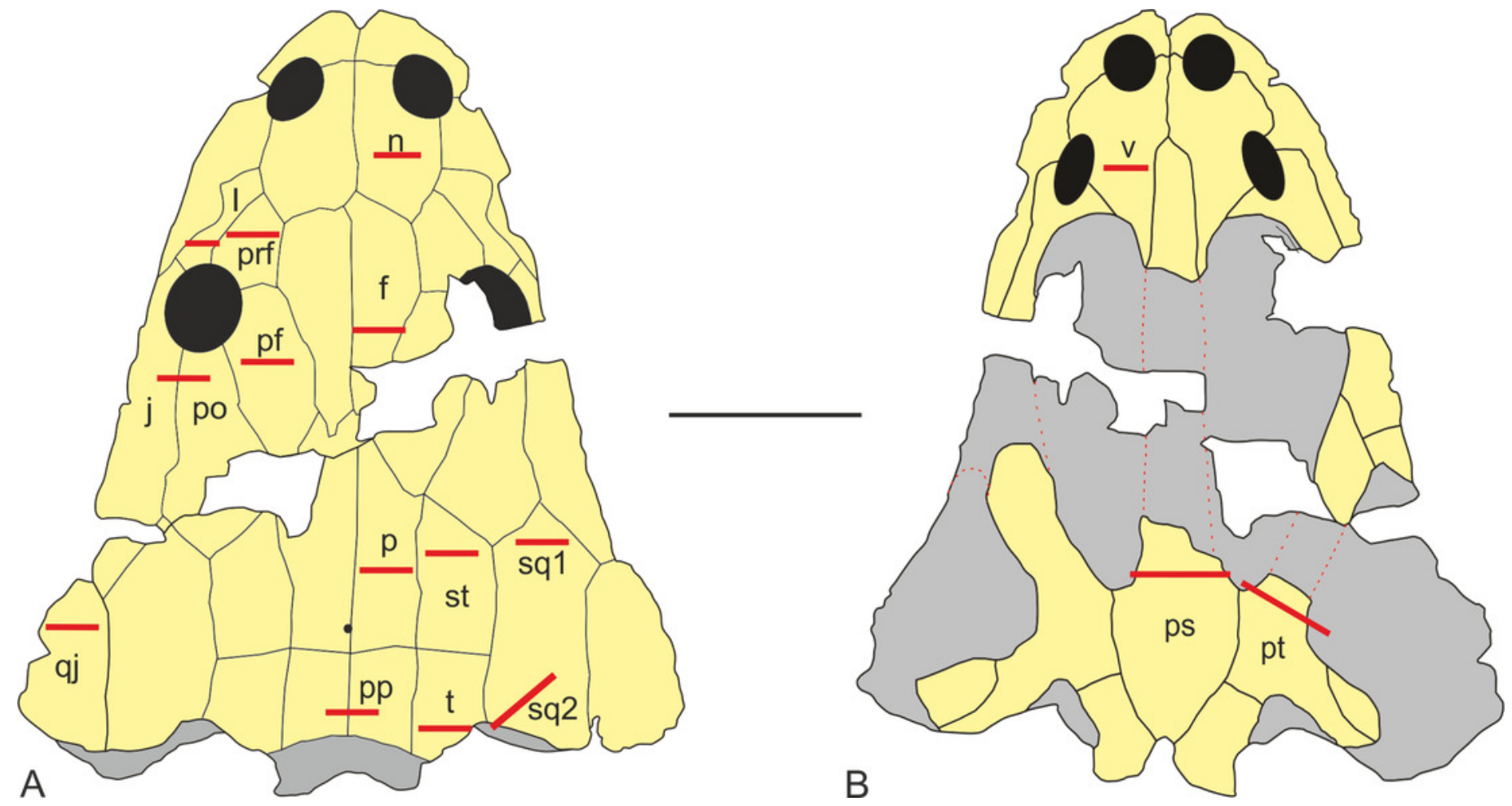
Figure 4

Von Mises stress results (in MPa) of bilateral (A), unilateral biting (B), lateral (C) and of skull raising system (D) in Metoposaurus krasiejowensis (UOPB 00124) using a gape angle of $10^{\circ}$.

ImageCredit: Journal of Anatomy/Wiley.
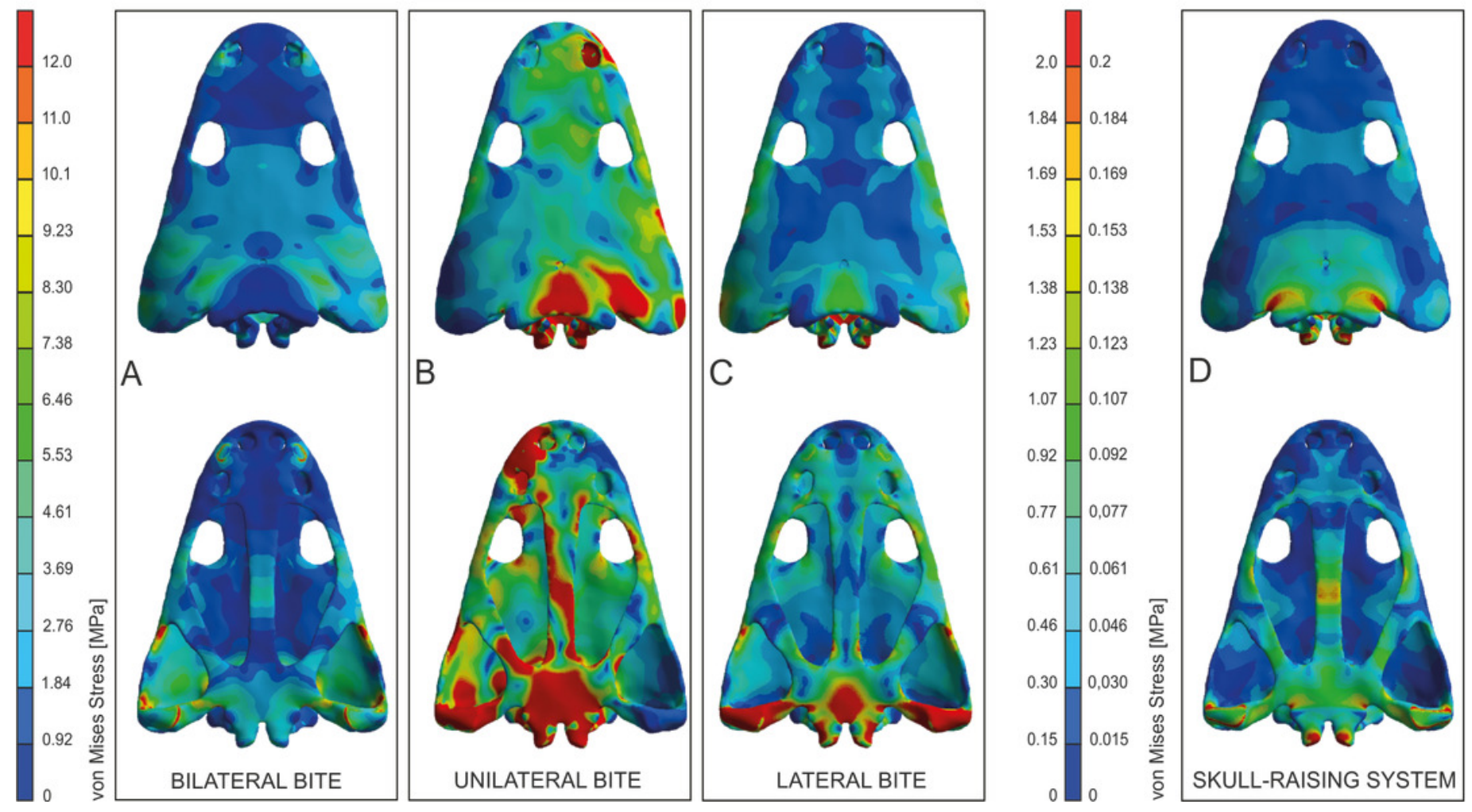


\section{Figure 5}

General microstructure of skull bones in Metoposaurus krasiejowensis (UOPB 01029).

All bones are shown in the same scale, whereas the skull miniatures are included only to show the position of bones and are not in scale. Scale bar equals $10 \mathrm{~mm}$. 


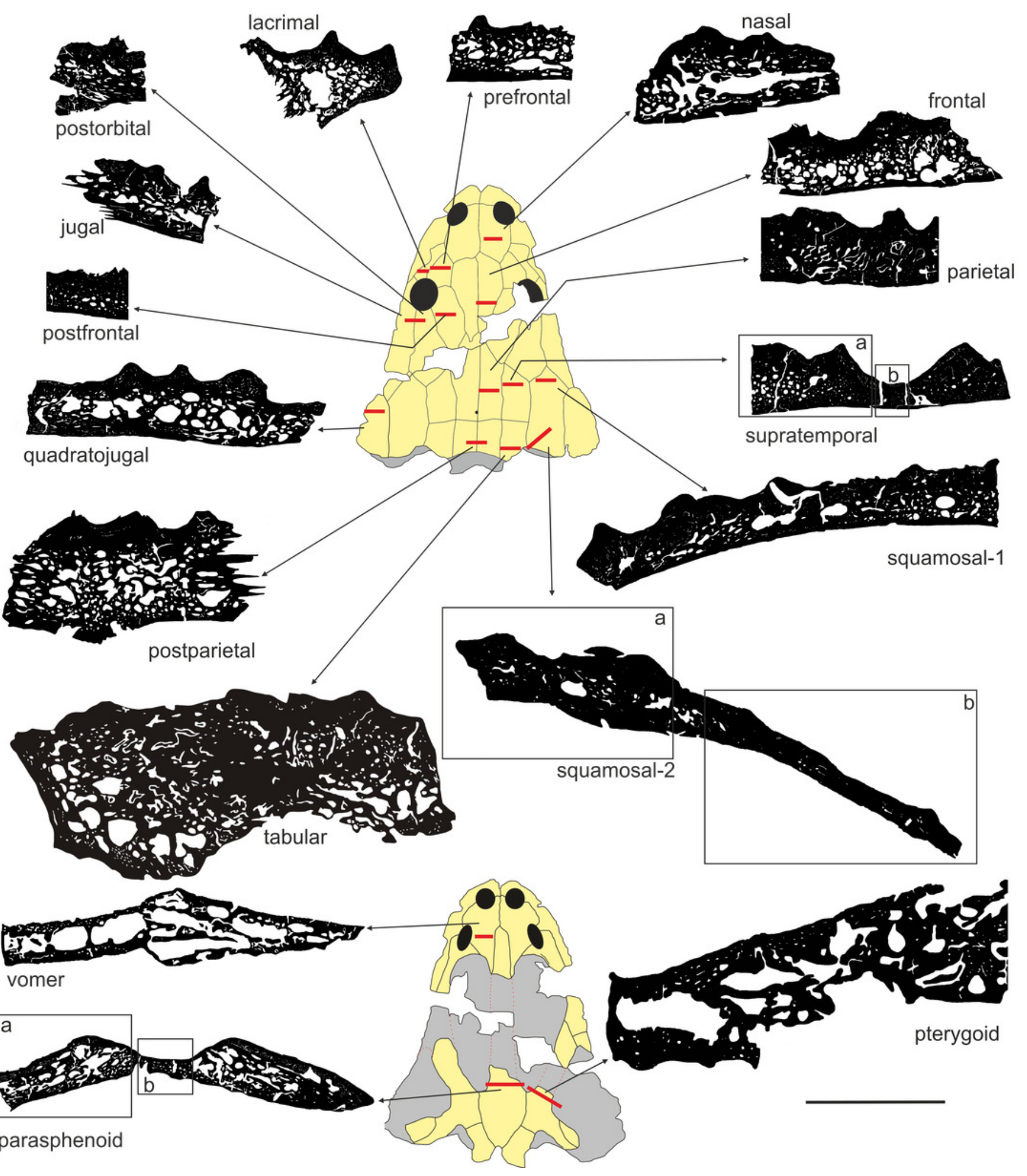




\section{Figure 6}

Estimated biomechanical loading as reconstructed on the basis of microstructural characters of the skull of Metoposaurus krasiejowensis (UOPB 01029).

Note that the estimated values (average bone thickness vs compactness) are relative and show merely if loading on any given region was higher or lower (on the scale bar from red to blue, respectively). It is not possible to calculate the objective amount of stress in this case. Black bars inside colour ellipses indicate the sectioning places; the ellipses without bars are symmetrical to sectioned areas.

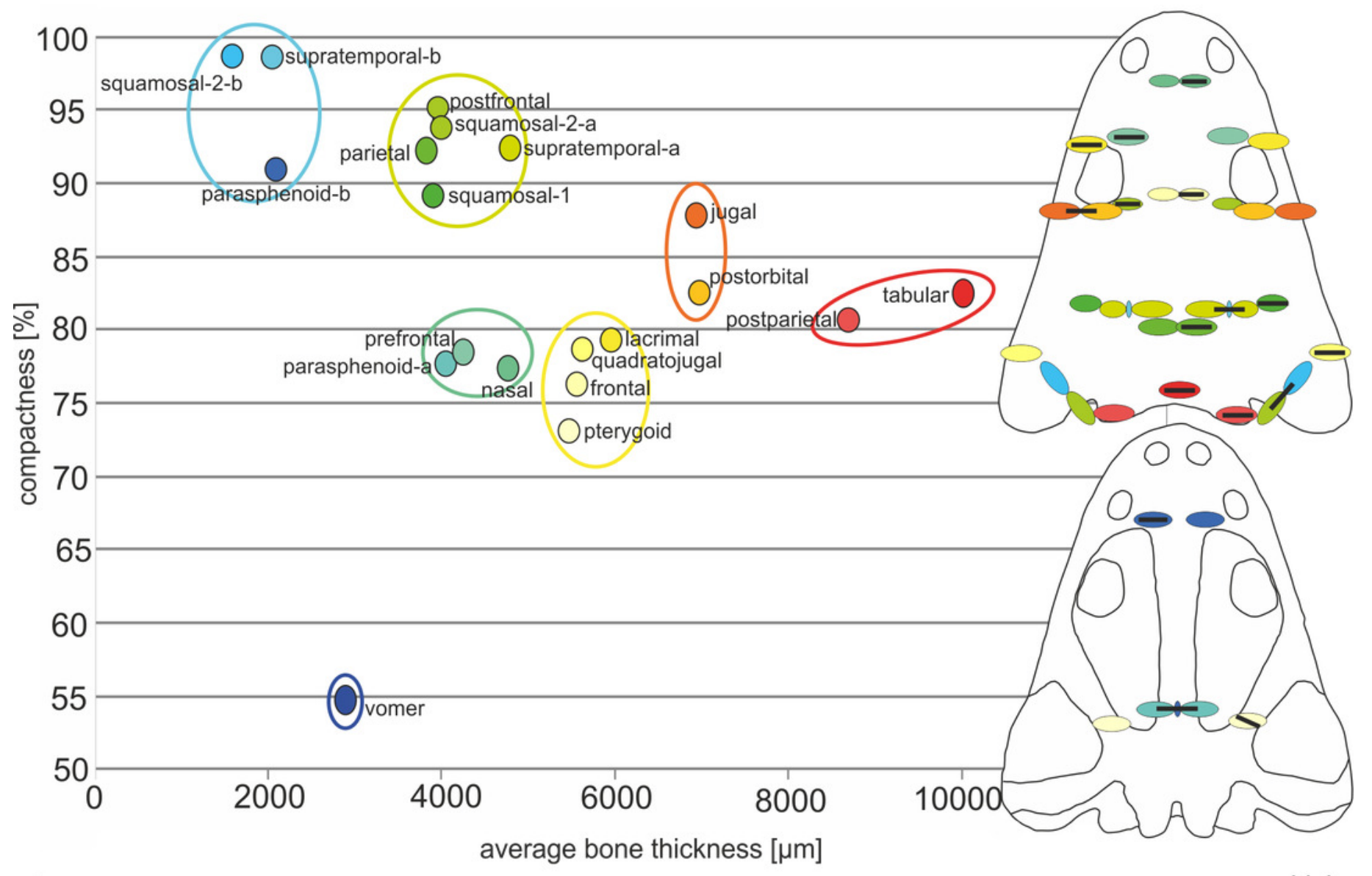

low

stress level as reconstructed from bone microstructure 


\section{Figure 7}

Von Mises stress results merged with the model of biomechanical loading created on the basis of microstructural characters.

Von Mises stress results represent unilateral (A), bilateral (B), lateral (C) biting and of skullraising system (D) in Metoposaurus krasiejowensis (UOPB 00124) using a gape angle of $10^{\circ}$. Model of biomechanical loading is created on the basis of microstructural characters for skull UOPB 01029. Skulls in the background show FEA results; the outcome of histological reconstructions is illustrated as oval forms, of different colours. Note that similar colours were used in FEA analysis and histological estimates in order to illustrate how the general stress distribution in FEA and histological analyses correlate; however, identical colours do not signify identical stress values. In FEA, the colours refer to objective values (compare with Figure 4), while in histological models estimated values are relative and show merely if the loading on any given region is higher or lower within a single skull (on the scale bar from red to blue, which means from high to low loading, respectively). Black bars inside colour ellipses indicate the sectioning places; the ellipses without bars are symmetrical to section areas. The black dotted lines shows the sutures, the red lines indicate the reconstructed borders. 

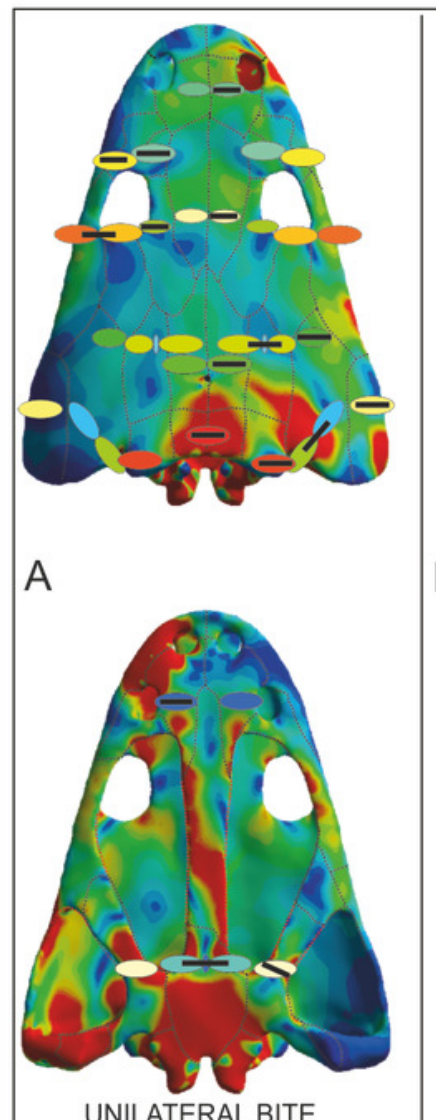

UNILATERAL BITE
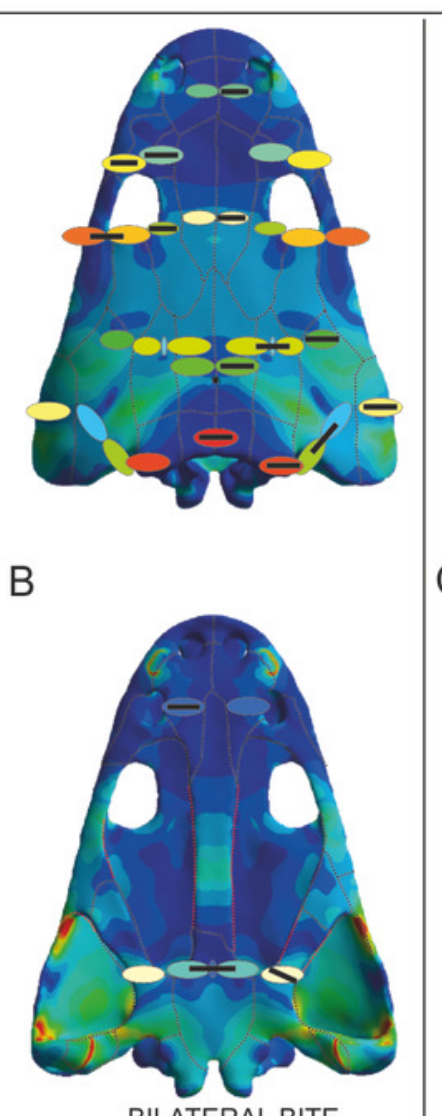

BILATERAL BITE
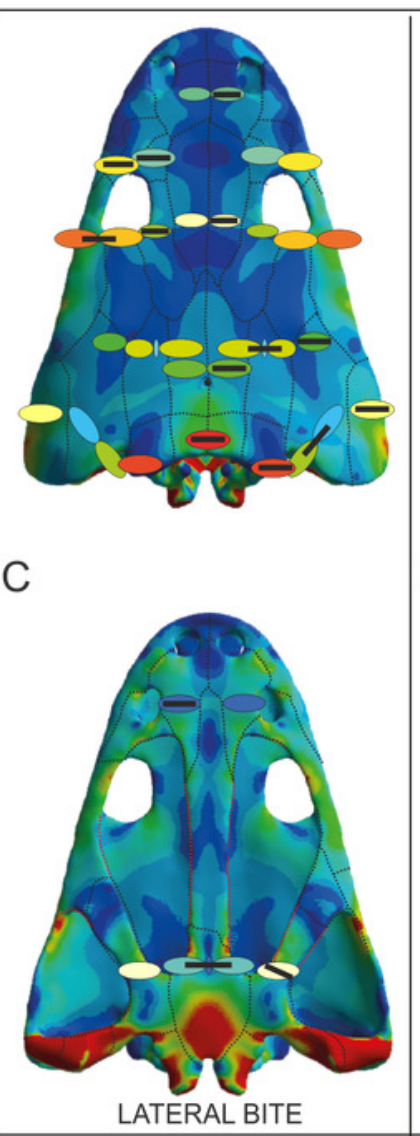

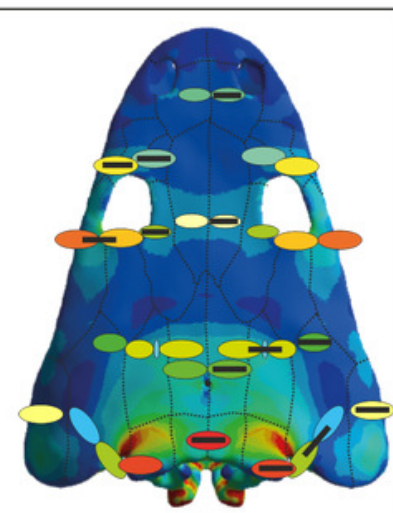

D

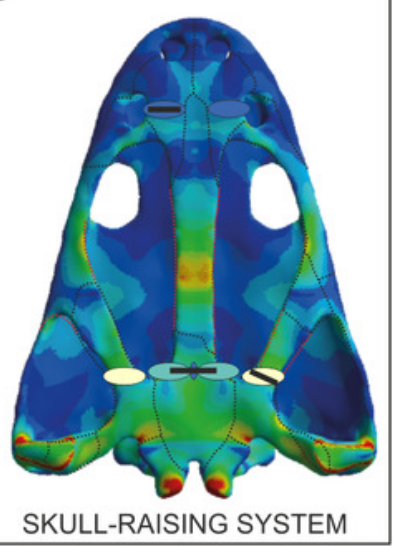

